\title{
Do Sunspots Matter When Spot Market Equilibria are Unique?
}

\author{
Hens, Thorsten
}

DOI: https://doi.org/10.1111/1468-0262.00117

Posted at the Zurich Open Repository and Archive, University of Zurich ZORA URL: https://doi.org/10.5167/uzh-192369

Journal Article

Published Version

Originally published at:

Hens, Thorsten (2000). Do Sunspots Matter When Spot Market Equilibria are Unique? Econometrica, 68(2):435-441.

DOI: https://doi.org/10.1111/1468-0262.00117 
Do Sunspots Matter When Spot Market Equilibria are Unique?

Author(s): Thorsten Hens

Source: Econometrica, Mar., 2000, Vol. 68, No. 2 (Mar., 2000), pp. 435-441

Published by: The Econometric Society

Stable URL: https://www.jstor.org/stable/2999435

REFERENCES

Linked references are available on JSTOR for this article:

https://www.jstor.org/stable/2999435?seq=1\&cid=pdf-

reference\#references_tab_contents

You may need to $\log$ in to $\bar{J}$ STOR to access the linked references.

JSTOR is a not-for-profit service that helps scholars, researchers, and students discover, use, and build upon a wide range of content in a trusted digital archive. We use information technology and tools to increase productivity and facilitate new forms of scholarship. For more information about JSTOR, please contact support@jstor.org.

Your use of the JSTOR archive indicates your acceptance of the Terms \& Conditions of Use, available at https://about.jstor.org/terms 


\title{
DO SUNSPOTS MATTER WHEN SPOT MARKET \\ EQUILIBRIA ARE UNIQUE?
}

\author{
By THORSTEN HENS ${ }^{1}$
}

\section{INTRODUCTION}

THE PURPOSE OF THIS NOTE is to clarify the relationship between the uniqueness of spot market equilibria and the existence of sunspot equilibria. The framework chosen is a standard, two period, competitive change economy with sunspot-dependent real assets. There is no uncertainty except for sunspots. It is demonstrated by an example with Cobb-Douglas preferences and numéraire assets that sunspot equilibria exist, even though spot market equilibria are unique for all distributions of ex-post endowments that can be reached by using ex-ante asset trade. Hence our example demonstrates that the existence of sunspot equilibria does not necessarily rely on an argument based on the multiplicity of spot market equilibria. This is remarkable since sunspot equilibria have often been identified with perfect foresight equilibria where agents' expectations over multiple spot market equilibria are coordinated by some exogenous random event: the sunspot. Clearly sunspots can be used as a coordination device of expectations, but from a more general perspective sunspot equilibria are any equilibria in which the equilibrium allocation depends on some exogenous random event. Our example demonstrates that the latter may well be the case without the former.

The literature in which sunspot equilibria and multiplicity of spot market equilibria get related in two period exchange economies can be divided along the assumption of whether assets are nominal or real. When assets are nominal, in general, spot market equilibria are not even locally unique. Sunspot equilibria can then be detected by demonstrating that the set of nonsunspot equilibria is of strictly smaller dimension than the set of all equilibria, whose dimension is called the "indeterminacy." For this branch of the sunspot literature see Cass (1989) and generalizations of it. With real assets spot market equilibria are generically locally unique but not necessarily globally unique. Guesnerie and Laffont (1988) give an example in which an incomplete set of real assets can be traded contingent upon the occurrence of a sunspot. In their example sunspot equilibria exist when the underlying fundamental economy, which is the economy without the sunspot uncertainty, has multiple equilibria.

Mas-Colell (1992) pointed out that sunspot equilibria might still exist even if the underlying fundamental economy might have a unique equilibrium. In Mas-Colell's example agents trade in (sunspot-independent real) assets towards an ex-post allocation of endowments for which the underlying economy has multiple equilibria among which the sunspot is used as a coordination device. Recently, Gottardi and Kajii (1999) have

\footnotetext{
${ }^{1}$ This paper is a revision of some work that I did during my second year, spent at DELTA, in the European Doctoral Program. I would like to thank the people from DELTA for their hospitality. I am especially indebted to my local supervisor, Roger Guesnerie, who continuously encouraged me to solve this problem. Furthermore I am grateful to a co-editor and three anonymous referees of this journal. Financial support by Deutsche Forschungsgemeinschaft, Sonderforschungsbereich 303 at the University of Bonn is gratefully acknowledged.
} 
generalized Mas-Colell's example. They demonstrate that for a generic set of utility functions the underlying exchange economy always has a non-empty region of endowment distributions so that for some open set of sunspot-independent assets, trade towards these regions of endowments induces sunspot equilibria.

In this note the framework of Mas-Colell's (1992) example is used but in contrast to him and Gottardi and Kajii (1999) we will choose assets such that spot market equilibria are unique for all allocations of ex-post endowments that can be reached by using ex-ante asset trade. Our example demonstrates that sunspots can still matter. For this to be true assets have to payoff differently across sunspot states. If payoffs were not sunspot-dependent, then, irrespectively of the particular realization of the sunspot event, the ex-post spot market economies would be identical and because of our strong uniqueness requirement they would have the same equilibrium, so that sunspots will not matter.

\section{THE EXAMPLE}

We consider a standard, two period, competitive exchange economy. There are $s=1,2,3$ sunspot states in the second period. There is no uncertainty except for sunspots. At the beginning of the second period, sunspot state $s=1,2,3$ occurs with a publicly known probability $\pi(s)>0$. Spot commodity markets open in the second period only. There are two commodities in each spot. Commodity 2 is a designated numéraire of the economy. We let $p(s)$ denote the first commodity's price in terms of the numéraire. There are two assets, in zero net supply, that are traded in the first period and yield payoffs in terms of the numéraire. Asset 2 pays one unit of the numéraire if and only if sunspot-state one occurs. Asset 1 does not pay off anything in state one but it pays $b(c)$ units of the numéraire if state two (three) occurs. Hence the nominal returns of the assets are given by the $3 \times 2$ matrix

$$
V=\left[\begin{array}{ll}
0 & 1 \\
b & 0 \\
c & 0
\end{array}\right]
$$

in which rows correspond to states and columns correspond to assets. In the first period we take asset 2 to be the numéraire, i.e. $q \in \mathbb{R}$ denotes the first asset's price while that of the second asset is normalized to 1 .

There are two households denoted by $i=1,2$. Household 1 (2) is endowed with one unit of good 1 (2), i.e. initial endowment vectors are $\omega^{1}=(1,0)$ and $\omega^{2}=(0,1)$. The households' preferences over the two commodities are given by the Cobb-Douglas preferences

$$
u^{i}: \mathbb{R}_{+}^{2} \rightarrow \mathbb{R}, \quad u^{i}\left(x_{1}, x_{2}\right)=\hat{h}^{i}\left(x_{1}^{\alpha^{i}} x_{2}^{1-\alpha^{i}}\right), \quad 0<\alpha^{i}<1
$$

where $\hat{h}^{i}: \mathbb{R}_{+} \rightarrow \mathbb{R}$ is a differentiable, strictly monotone and strictly concave function, $i=1,2$.

If the distinction among the sunspot states is ignored, we have a deterministic economy $G E=\left[\mathbb{R}^{2},\left(u^{i}, \omega^{i}\right)_{i=1,2}\right]$. We call $G E$ the underlying economic fundamentals.

In principle agents do not rule out the possibility that the sunspot might affect the consumption allocation and ex-ante they evaluate risky consumption plans $x \in \mathbb{R}_{+}^{2 \cdot 3}$

\footnotetext{
This content downloaded from

130.60.131.95 on Tue, 24 Nov 2020 09:11:49 UTC

All use subject to https://about.jstor.org/terms
} 
according to the expected utility criterion

$$
U^{i}(x)=\sum_{s=1}^{3} \pi(s) u^{i}(x(s)), \quad i=1,2 .
$$

We can summarize an agent's decision problem in the sunspot economy $G E I=$ $\left[\mathbb{R}^{2 \cdot 3},\left(U^{i}, \omega^{i}\right)_{i=1,2}, V\right]$ by

$$
\begin{aligned}
& \max _{x \in \mathbb{R}_{+}^{2 \cdot 3}, \theta \in \mathbb{R}^{2}} \sum_{s=1}^{3} \pi_{(s)} u^{i}(x(s)) \quad \text { subject to } \\
& \\
& q \theta_{1}+\theta_{2} \leq 0 \\
& \\
& p(s) x_{1}(s)+x_{2}(s) \leq p(s) \omega_{1}^{i}+\omega_{2}^{i}+V(s) \theta, \quad s=1,2,3 .
\end{aligned}
$$

An equilibrium for the GEI economy is an asset price $\stackrel{\star}{q}$, a vector of correctly foreseen spot prices $\bar{p} \in \mathbb{R}^{3}$ and an allocation of assets and commodities $(\stackrel{\star}{\theta}, \grave{x}) \in \mathbb{R}^{2 \cdot 2} \times \mathbb{R}^{2 \cdot 3 \cdot 2}$ such that:

(i) $\left(\stackrel{\star}{*}^{i}, \grave{x}^{i}\right)$ solves $\left(M^{i}\right)$ given $(\stackrel{\star}{q}, \grave{p}), i=1,2$;

(ii) $\hbar^{1}=-\hbar^{2}$;

(iii) $\star^{1}(s)+\hbar^{2}(s)=\omega^{1}+\omega^{2}, s=1,2,3$.

It is important to note that the value of the consumption of household $i$ in every state $s$ is bounded by the value of its ex-post endowments $\hat{\omega}^{i}(s)$, where $\hat{\omega}_{1}^{i}=\omega_{1}^{i}$ and $\hat{\omega}_{2}^{i}(s)=\omega_{2}^{i}+V(s) \theta^{i}, s=1,2,3, i=1,2$. Thus an equilibrium of the GEI-economy can be thought of as a collection of equilibria for the three ex-post exchange economies $G E(s)=\left[\mathbb{R}^{2},\left(u^{i}, \hat{\omega}^{i}(s)\right)_{i=1,2}\right]$ together with an asset market equilibrium determining $\hat{\omega}^{i}(s), s=1,2,3, i=1,2$.

Note that there is always one GEI-equilibrium, in which the same allocation is obtained in all three sunspot states and in which assets are not traded. This nonsunspot equilibrium can naturally be identified with the unique equilibrium of the certainty economy $G E$. So the standard fixed point argument to demonstrate existence of competitive equilibria might just show existence of a nonsunspot equilibrium. Moreover, as demonstrated in Hens (1991) this equilibrium is always determinate so that unlike the case of nominal assets there is no useful parameterization of equilibria that might help us to generate sunspot equilibria, e.g. via a bifurcation around nonsunspot equilibria (cf. Hens (1991)).

For these reasons our example relies on a constructive argument. To save indices let $\alpha$ denote $\alpha^{1}, \beta$ denote $\alpha^{2}, \hat{h}$ denote $\hat{h}^{1}$ and let $\hat{g}$ denote $\hat{h}^{2}$.

First note that by the choice of the utility functions and the asset structure the two agents will never be able to trade towards an ex-post endowment distribution $\left(\hat{\omega}^{1}(s)\right.$, $\left.\hat{\omega}^{2}(s)\right)$ in some state $s \in\{1,2,3\}$ for which the ex-post exchange economy $\left[\mathbb{R}^{2},\left(u^{i}\right.\right.$, $\left.\hat{\omega}^{i}((s))_{i=1,2}\right]$ has multiple equilibria. By choice of the utility functions, for all but one distribution of endowments $\left(\tilde{\omega}^{i}\right)_{i=1,2}$, we get a unique equilibrium. For

$$
\tilde{\omega}^{1}=\left(\frac{1-\beta}{\alpha-\beta},-\frac{\beta}{\alpha-\beta}\right)
$$

there is a continuum of equilibria in which relative prices and the equilibrium allocation are indeterminate. However, trading from the initial endowments $\omega^{1}=(1,0), \omega^{2}=(0,1)$ towards these particular endowments would require assets to pay off in both consumption goods!

\footnotetext{
This content downloaded from

130.60.131.95 on Tue, 24 Nov 2020 09:11:49 UTC

All use subject to https://about.jstor.org/terms
} 
A second conclusion that can be drawn from the strong uniqueness property of our example is that any asset trade necessarily leads to consumption and utility allocations that differ across sunspot states. With Cobb-Douglas preferences, spot prices are strictly positive; therefore, trading numéraire assets means changing the relative income distribution across sunspot states. And as long as preferences are not identical (i.e. $\alpha \neq \beta$ ) equilibrium prices and equilibrium allocations will differ across states. Figure 1 displays the set of Pareto-efficient allocations for the Cobb-Douglas economy with $\alpha \neq \beta$. Moving endowments vertically clearly changes the equilibria. Thus, in our example, sunspots matter if and only if assets are actually traded! The same can be observed in equations (1)-(3) that we derive on the next page.

Now we will show that an equilibrium exists in which assets are traded. For an illustration of this equilibrium see Figure 1.

To further simplify the notation note that since the second asset has a nonnegative and nonzero payoff vector, both agents will always satisfy their first period budget restriction with equality. The budget identities $q \theta_{1}^{i}+\theta_{2}^{i}=0, i=1,2$, and the market clearing condition $\theta^{1}=-\theta^{2}$ allow us to express all equilibrium asset holdings $\theta_{j}^{i}$, $i, j=1,2$ in terms of the single scalar $\theta$ which denotes $\theta_{1}^{1}$.

The following five equations characterize a GEI-equilibrium in our example:

$$
\begin{aligned}
& p(1)=\frac{(\beta-\alpha) q \theta+\beta}{1-\alpha}, \\
& p(2)=\frac{(\alpha-\beta) b \theta+\beta}{1-\alpha}, \\
& p(3)=\frac{(\alpha-\beta) c \theta+\beta}{1-\alpha},
\end{aligned}
$$

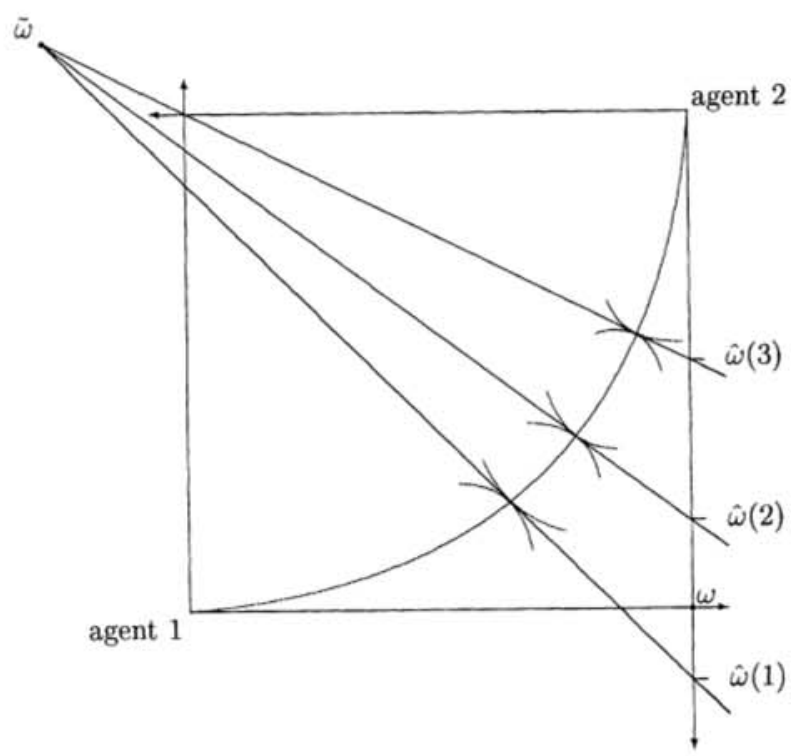

FIGURE 1 


$$
\begin{aligned}
& \frac{\pi(2) b}{p(2)^{\alpha}} \tilde{h}^{\prime}\left(\frac{p(2)+b \theta}{p(2)^{\alpha}}\right)+\frac{\pi(3) c}{p(3)^{\alpha}} \tilde{h}^{\prime}\left(\frac{p(3)+c \theta}{p(3)^{\alpha}}\right)=\frac{\pi(1) q}{p(1)^{\alpha}} \tilde{h}^{\prime}\left(\frac{p(1)-q \theta}{p(1)^{\alpha}}\right), \\
& \frac{\pi(2) b}{p(2)^{\beta}} \tilde{g}^{\prime}\left(\frac{1-b \theta}{p(2)^{\beta}}\right)+\frac{\pi(3) c}{p(3)^{\beta}} \tilde{g}^{\prime}\left(\frac{1-c \theta}{p(3)^{\beta}}\right)=\frac{\pi(1) q}{p(1)^{\beta}} \tilde{g}^{\prime}\left(\frac{1+q \theta}{p(1)^{\beta}}\right) .
\end{aligned}
$$

Equations (1)-(3) are the spot market equilibrium conditions, and equations (4)-(5) are the first order conditions for asset choice that characterize asset demand. Here, in order to simplify the expressions, $\tilde{h}^{\prime}(y)$ is defined by $\hat{h}^{\prime}\left(\alpha^{\alpha}(1-\alpha)^{1-\alpha} y\right)$ and $\tilde{g}^{\prime}(y)$ is defined by $\hat{g}^{\prime}\left(\beta^{\beta}(1-\beta)^{1-\beta} y\right)$.

To simultaneously solve these equations set $\theta=-1, \alpha=1 / 4$, and $\beta=1 / 2$ and insert (1)-(3) into (4) and (5). In order to achieve a further simplification we define auxiliary functions:

$$
\begin{aligned}
& \Psi_{1}(x):=\frac{x}{(2+x)^{1 / 4}} h^{\prime}\left(\frac{1-x}{(2+x)^{1 / 4}}\right), \\
& \Psi_{2}(x):=\frac{x}{(2+x)^{1 / 2}} g^{\prime}\left(\frac{1+x}{(2+x)^{1 / 2}}\right),
\end{aligned}
$$

where $h^{\prime}(y)$ is given by $\tilde{h}^{\prime}\left((3 / 16)^{1 / 4} y\right)$ and $g^{\prime}(y)$ is given by $\tilde{g}^{\prime}\left(3^{1 / 2} y\right)$.

Using these auxiliary functions, equations (4) and (5) can be reduced to

$$
\begin{aligned}
& \pi(2) \Psi_{1}(b)+\pi(3) \Psi_{1}(c)+\pi(1) \Psi_{1}(-q)=0, \\
& \pi(2) \Psi_{2}(b)+\pi(3) \Psi_{2}(c)+\pi(1) \Psi_{2}(-q)=0 .
\end{aligned}
$$

Equations (6) and (7) constitute a linear system in the probabilities $\pi(s), s=1,2,3$. Therefore, we solve (4) and (5) for $\pi(2)$ and $\pi(3)$, where $\pi(1)=1-\pi(2)-\pi(3)$. The solution is

$$
\begin{aligned}
& \pi(3)=\frac{Q_{2}\left(B_{1}-Q_{1}\right)-Q_{1}\left(B_{2}-Q_{2}\right)}{Q_{2}\left(B_{1}-Q_{1}\right)-Q_{1}\left(B_{2}-Q_{2}\right)+C_{1}\left(B_{2}-Q_{2}\right)-C_{2}\left(B_{1}-Q_{1}\right)}, \\
& \pi(2)=\frac{Q_{2}\left(C_{1}-Q_{1}\right)-Q_{1}\left(C_{2}-Q_{2}\right)}{Q_{2}\left(C_{1}-Q_{1}\right)-Q_{1}\left(C_{2}-Q_{2}\right)+B_{1}\left(C_{2}-Q_{2}\right)-B_{2}\left(C_{1}-Q_{1}\right)},
\end{aligned}
$$

where

$$
B_{i}=\Psi_{i}(b), \quad C_{i}=\Psi_{i}(c), \quad Q_{i}=\Psi_{i}(-q), \quad i=1,2 .
$$

The following three inequalities (8)-(10) are sufficient for the solution to satisfy $\pi(2)>0, \pi(3)>0$, and $\pi(2)+\pi(3)<1$ (hence $\pi(1)>0)$ :

$$
Q_{2} B_{1}>Q_{1} B_{2},
$$

$$
C_{1} B_{2}>C_{2} B_{1} \text {, }
$$

$$
Q_{2} C_{1}>Q_{1} C_{2} \text {. }
$$

In order to complete the proof we need to find two strictly concave functions $h, g$ and three values $b, c, q \in(-1,1)$ such that (8)-(10) are satisfied. Note that choosing $b, c, q \in$ $(-1,1)$ guarantees nonnegative ex-post income and hence nonnegative consumption $x^{i}(s), s=1,2,3, i=1,2$.

\footnotetext{
This content downloaded from 130.60.131.95 on Tue, 24 Nov 2020 09:11:49 UTC

All use subject to https://about.jstor.org/terms
} 
Observe that

(i) $\quad \Psi_{1}(0)=\Psi_{2}(0)=0$,

(ii) $\Psi_{i}(x)<0$ for $-1<x<0$,

and suppose we would find strictly concave functions $h, g$ so that

(iii) $\quad \Psi_{1}^{\prime}(0)>\Psi_{2}^{\prime}(0)>0$,

(iv) $\quad \Psi_{1}(-1)>\Psi_{2}(-1)$,

(v) $\quad \Psi_{1}^{\prime \prime}(0)<\Psi_{2}^{\prime \prime}(0)<0$.

Then from the continuity of $\Psi_{i}$ and (i)-(iv) we find $\hat{x} \in(-1,0)$ such that $\Psi_{1}(\hat{x})=\Psi_{2}(\hat{x})$ $<0$.

Choosing $q=-\hat{x}>0$ simplifies (8)-(10) to

(8') $\quad B_{1}<B_{2}$,

(9') $\quad C_{1} B_{2}>C_{2} B_{1}$,

(10') $\quad C_{1}>C_{2}$.

If, in addition, (v) holds, we would get the existence of $b, c$ with $-1<b<0, q\rangle c\rangle 0$ (see Figure 2 ) leading to $\left(8^{\prime}\right)-\left(10^{\prime}\right)$ being satisfied. Thus, it remains to argue that there exist two strictly concave functions $h, g$ that satisfy (iii)-(v).

To see that this is possible we compute (iii)-(iv) explicitly. Thus (iii)-(v) are satisfied if

(iii) $\quad 2^{-1 / 4} h^{\prime}\left(2^{-1 / 4}\right)>2^{-1 / 2} g^{\prime}\left(2^{-1 / 2}\right)$,

(iv) $\quad h^{\prime}(2)<g^{\prime}(0)$,

(v) $\quad 2^{-5 / 4} h^{\prime}\left(2^{-1 / 4}\right)>2^{-3 / 2} g^{\prime}\left(2^{-1 / 2}\right)$ and $h^{\prime \prime}\left(2^{-1 / 4}\right) \sim 0, \quad g^{\prime \prime}\left(2^{-1 / 2}\right) \sim 0$,

which is compatible with $g, h$ being strictly concave in the range $[0,2]$ (see Figure 3 ).

This ends our construction.

We conclude this section with two final remarks.

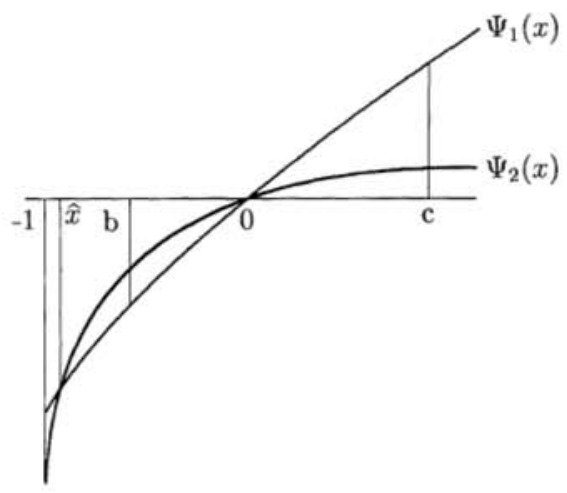

Figure 2 


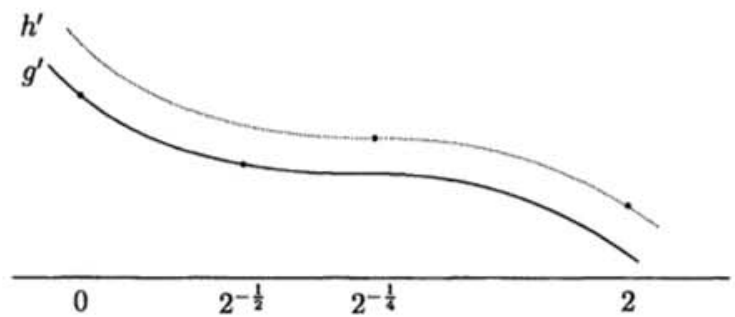

FIGURE 3

As can be seen from Figure 3, our construction uses the property that for both agents the degree of risk aversion is not constant. Constant risk aversion is known-under certain conditions - to imply uniqueness of financial market equilibria (cf. e.g. Hens and Löffler (1995) and Milne (1979)).

Finally, note that from the construction of the example we see that the occurrence of the sunspot equilibrium is robust against small perturbations of the economic fundamentals $\left(u^{i}, \omega^{i}\right)_{i=1,2}$. For any slightly different economic fundamentals we shall find expectations $\pi \in \mathbb{R}_{+}^{3}$, an asset structure and risk aversion functions $h, g$ that solve the equilibrium conditions (1)-(5). We have argued that a sufficient condition for the solution of (1)-(5) is the system of strict inequalities (8)-(10).

University of Zurich, Institute for Empirical Economic Research, Bluemlisalpstr.10, CH-8006 Zurich, Switzerland; thens@iew.unizh.ch

Manuscript received 1991; final revision received February, 1999.

\section{REFERENCES}

CASs, D. (1989): "Sunspots and Incomplete Financial Markets: The Leading Example," in The Economics of Imperfect Competition and Employment: Joan Robinson and Beyond, ed. by G. Feiwel. London: MacMillan.

GotTARDI, P., AND A. KAлI (1999): "The Structure of Sunspot Equilibria: The Role of Multiplicity," Review of Economic Studies, 66, 713-732.

GUesnerie, R., AND J. J. LAFFONT (1988): "Notes on Sunspot Equilibria in Finite Economics, in Volume en l'Honneur d'Edmont Malinvaud, Economica-EHESS. Cambridge, MA: MIT Press (English version), pp. 118-143.

Hens, TH. (1991): "Sunspot Equilibria in Finite Horizon Models with Incomplete Markets," SFB 303 Discussion Paper No. A-354, University of Bonn.

Hens, TH., AND A. LöFfler (1995): “Gross Substitution in Financial Markets," Economics Letters, 49, 39-43.

Mas-Colell, A. (1992): "Three Observations on Sunspots and Asset Redundancy," in Economic Analysis of Markets and Games: Essays in Honor to Frank Hahn, ed. by P. Dasgupta, D. Gale, O. Hart, and F. Maskin. Cambridge, MA: MIT Press.

MILNE, F. (1979): "Consumer Preferences, Linear Demand Functions and Aggregation in Competitive Asset Markets," Review of Economic Studies, 46, 407-417. 